\title{
Mechanical and Oxygen Barrier Properties of LDPE/MMT/MAPE and LDPE/MMT/EVA Nanocomposite Films: A Comparison Study
}

\author{
Khaliq Majeed, ${ }^{1,2}$ Reza Arjmandi ${ }^{1}$ and Azman Hassan ${ }^{1 *}$ \\ ${ }^{1}$ Department of Bioprocess and Polymer Engineering, Faculty of Chemical and Energy \\ Engineering, Universiti Teknologi Malaysia, 81310 Skudai, Johor Bahru, Malaysia \\ ${ }^{2}$ Department of Chemical Engineering, COMSATS Institute of Information Technology, \\ Lahore, Pakistan
}

*Corresponding author: azmanh@cheme.utm.my

Published online: 25 April 2018

To cite this article: Majeed, K., Arjmandi, R. \& Hassan, A. (2018). Mechanical and oxygen barrier properties of LDPE/MMT/MAPE and LDPE/MMT/EVA nanocomposite films: A comparison study. J. Phys. Sci., 29(1), 43-58, https://doi.org/10.21315/jps2018.29.1.4

To link to this article: https://doi.org/10.21315/jps2018.29.1.4

\begin{abstract}
Enhanced mechanical and barrier properties are of special interest in food packaging industries, in which uniform dispersion of nanoparticles in polymers confers considerable improvement in these properties. In this study, maleic anhydride grafted polyethylene (MAPE) and ethylene vinyl acetate (EVA) compatibilised low density polyethylene/montmorillonite (LDPE/MMT) nanocomposite films were prepared with different concentrations of the compatibilisers by melt mixing technique. The delamination of MMT layers was evidenced from X-ray diffraction results that suggested an increase in the interlayer distance with the addition of compatibilisers, where MAPE is the better compatibiliser in delaminating MMT platelets in LDPE/MMT nanocomposites compared to EVA. The mechanical and barrier properties of compatibilised LDPE/MMT nanocomposites were better than uncompatibilised nanocomposites. The best improvement in tensile strength, tear strength and oxygen barrier were observed for LDPE/MMT/MAPE nanocomposites. However, the best improvements in elongation at break were seen for the LDPE/MMT nanocomposites compatibilised with EVA. Conclusively, MAPE compatibiliser is more effective in delaminating MMT platelets in LDPE/MMTnanocomposites, enhancing the mechanical and barrier properties of the nanocomposites. Results revealed that the optimum content of MAPE in terms of mechanical and barrier properties is 3 phc. The enhanced tensile and barrier properties of LDPE/MMT films with the incorporation of $M A P E$ suggest a great potential of these nanocomposite films in food packaging.
\end{abstract}

Keywords: Compatibilisers, comparison, nanocomposites, tensile properties, oxygen barrier properties. 


\section{INTRODUCTION}

Polyethylene films are used in many applications, including food stuff and goods packaging, agriculture and merchandising. Their popularity in the plastic industry is due to their low production cost and product cost, easy processability, high flexibility, impact toughness and high resistant to moisture. ${ }^{1,2}$ These films have been used for food packaging, but fall short in providing an enhanced shelf life for oxygen and moisture sensitive foods due to their low barrier. This higher permeability to oxygen and water vapour may lead to loss of flavour components and vitamins through oxidation. It is well documented that one of the most important requirements for the use of plastics in food packaging is impermeability to oxygen and water vapour. Generally, multilayer structures are used for improved barrier properties, however, the recycling of multilayer films is still an important problem. ${ }^{3,4}$

Recently, a class of new materials represented by nanocomposites has proven to be a promising option to improve the mechanical and barrier properties. Polymer/clay nanocomposites (PCNs), where impermeable lamellar fillers having at least one dimension in the nanometre range are incorporated into polymer matrix, become a promising strategy for fabricating high barrier films, since they may lead to enhanced barrier properties with far less filler content than conventional composite films. ${ }^{5}$ The concept of PCNs was developed after the first successful application of polyamide-6/montmorillonite (MMT) nanocomposite material developed by the Toyota Corporation in $1986 .{ }^{6}$ However, studies on the development of PCN-based food packaging materials have been published only since the late $1990 \mathrm{~s}^{7}$ Several nanoparticles have been recognised as possible additives to enhance polymer performance. Among all the potential nanofillers, the prototypical clay utilised in food contact applications is MMT. ${ }^{7}$ To realise the large filler aspect ratio and to take full advantage of the reinforcement and/or tortuosity clay particles can provide to the nanocomposites, they must be exfoliated into single platelets, distributed homogeneously and oriented in the appropriate direction into the continuous phase. The main issue in the preparation of PCNs is the intercalation of polymer chains between the layers of clay; high level of dispersion and ultimately full exfoliation of clay platelets within the polymer matrix. Non-polar polymers like polyethylene face difficulty in establishing a well bonded structure and intercalation of polymer chains in the galleries of clay layers. Therefore, most successful research works of high barrier nanocomposites are based on hydrophilic polymer matrix, such as nylon. ${ }^{5}$ On the other hand, the nanometer level exfoliation and uniform dispersion of the clay particles in hydrophobic matrix is still a key issue to be resolved. 
The clay in a nanocomposite may be intercalated or exfoliated or have a mixed morphology, depending on the strength of the interfacial interactions between matrix and clay particles, which ultimately affects the degree of dispersion of clay platelets. ${ }^{8}$ Many research works have been focused to improve the dispersion and exfoliation of clays in polyolefin matrices and the use of compatibilisers having compatibility with both, the matrix and reinforcement is a popular choice. For instance, Hong and Rhim studied the tensile and barrier properties of linear low density polyethylene (LLDPE)/MMT nanocomposite blown films and reported slightly intercalated nanocomposites with decrease in tensile and water vapour barrier properties. ${ }^{9}$ They suggested the use of maleic anhydride grafted PE and ethylene vinyl acetate to enhance compatibility between LLDPE and MMT that will lead to improved properties.

Pereira de Abreu et al. investigated the effect of incorporating polypropylene grafted maleic anhydride (MAPP) as compatibiliser into polypropylene (PP)/ MMT system and polyethylene grafted maleic anhydride (MAPE) into LDPE/ MMT system. ${ }^{10}$ The compatibilisers have been found to improve the compatibility between the matrix and the filler. A significant improvement was observed in tensile modulus of the nanocomposite polypropylene as compared to neat polypropylene with the tensile strength of both remained nearly same. In the case of permeability of both nanocomposite films, $29 \%$ reduction in oxygen transmission rate was observed for PP nanocomposite film while a $15 \%$ in the case of LDPE film. Chiu et al. studied the effect of two different compatibilisers, MAPP and MAPE on the properties of PP/high density polyethylene (HDPE) blend based MMT nanocomposites. ${ }^{11}$ The authors reported improved dispersion in the presence of compatibilisers and the dispersion was better in the presence of MAPE. Minkova and Filippi prepared the nanocomposites based on blends of HDPE/HDPE-g-MA, LDPE/LDPE-g-MA and LLDPE/LLDPE-g-MA and investigated the influence of maleated compatibiliser. ${ }^{12}$ They concluded that the MMT peaks in XRD disappeared only at higher content of the compatibiliser. To observe MMT delamination at lower content of compatibiliser, the concentration of MMT also has to reduce.

Ethylene vinyl acetate (EVA) is the copolymer of ethylene and vinyl acetate parts formed via free radical polymerisation with properties of high impact strength, good ageing resistance, high moisture absorption and low tensile strength. ${ }^{13}$ There are reports of well dispersed MMT in polyethylene with the addition of EVA as compatibiliser. For example, Dadfar et al. investigated the influence of EVA compatibiliser of the tensile and barrier properties of LDPE/MMT nanocomposite films and reported that the incorporation of the EVA resulted in significant increase in the $d$-spacing of MMT in the nanocomposites. ${ }^{14}$ Further, the oxygen barrier properties of the LDPE/EVA/nanoclay film were found much better than those of 
the LDPE/nanoclay film without EVA. Marini et al. studied the compatibilisation effect of EVA for HDPE/MMT system and reported decreased tensile and barrier properties in comparison to the neat HDPE. ${ }^{15}$ In another study to evaluate the effectiveness of EVA as compatibiliser on the oxygen permeability and the mechanical and thermal properties of LDPE/MMT system, the authors reported a significant increase in the interlayer spacing of MMT with the addition of EVA. ${ }^{16}$ The LDPE/EVA/MMT films had significantly lower permeability and the tensile properties were better than those without EVA.

The use of MAPE and EVA as compatibilisers for MMT filled polyethylene nanocomposites have been reported previously. ${ }^{11,12,16,17}$ In the present study, the effects of MAPE and EVA content on the mechanical and barrier properties of LDPE/MMT nanocomposite films were investigated and compared. To the best of our knowledge, no similar study has been reported in the open literature.

\section{EXPERIMENTAL}

\subsection{Materials}

Extrusion grade of LDPE (LDF200GG) was chosen as matrix material and natural MMT (Nanomer $\left.{ }^{\circledR} 1.44 \mathrm{P}\right)$ modified with quaternary ammonium salt with mean dry particle size of 15-20 $\mu \mathrm{m}$ were chosen as reinforcing filler to prepare mechanically stronger and high barrier LDPE/MMT nanocomposite films. No further details of the clay preparation and modification were disclosed by the manufacturer. MAPE (OREVAC $\left.{ }^{\circledR} 18365\right)$ and EVA copolymer (COSMOTHENE ${ }^{\circledR} \mathrm{H}-2181$ ) were chosen as compatibilisers for LDPE/MMT nanocomposites. Characteristic properties and manufacturer/supplier of the materials (obtained from manufacturers) used in this study are summarised in Table 1.

\subsection{Preparation of Nanocomposite Films}

MAPE and EVA compatibilised LDPE/MMT nanocomposites were prepared using a co-rotating Brabander twin extruder. The compositions of different LDPE nanocomposites have been prepared are shown in Table 2. Contents of MAPE and EVA were varied from 0 to 5 phc and 0 to 20 phc, respectively based on the previous studies to obtain optimum results..$^{10,14,16,18-21}$ The operating temperature of the extruder barrel was maintained at $160^{\circ} \mathrm{C}-170^{\circ} \mathrm{C}-170^{\circ} \mathrm{C}-180^{\circ} \mathrm{C}$ progressing from feeder to die zone with a screw speed of $50 \mathrm{rpm}$. The extruded strands were air-dried and pelletised using a pelletiser. The pellets were stored in sealed bags with appropriate markings to produce extrusion blown films. Blown film extrusion machine, Tai King (model: TK/HD, Tai King Machinery Factory Co. Ltd., Taiwan) 
was used to prepare LDPE and premixed LDPE/MMT blown films of around $50 \mu \mathrm{m}$ thickness. During the film blowing process, the temperature of the barrel was maintained at $130^{\circ} \mathrm{C}-140^{\circ} \mathrm{C}-160^{\circ} \mathrm{C}-170^{\circ} \mathrm{C}-160^{\circ} \mathrm{C}-140^{\circ} \mathrm{C}$ from feeder to die zone with a screw speed of $300 \mathrm{rpm}$.

Table 1: Characteristics of the materials.

\begin{tabular}{lll}
\hline Material & Specification & Manufacturer/supplier \\
\hline LDPE & MFI $=2 \mathrm{~g} / 10 \mathrm{~min}$ & Titan Chemicals, Malaysia \\
& $\begin{array}{l}\text { Density }=0.922 \mathrm{~g} \mathrm{~cm}^{-3} \\
\text { Vicat softening point }=95^{\circ} \mathrm{C}\end{array}$ & \\
& Melting temperature $=160^{\circ} \mathrm{C}-180^{\circ} \mathrm{C}$ & \\
MAPE & MFI $=2.5 \mathrm{~g} / 10 \mathrm{~min}$ & Arkema, France \\
& Density $=0.916 \mathrm{~g} \mathrm{~cm}^{-3}$ & \\
& Vicat softening point $=90^{\circ} \mathrm{C}$ & \\
& Melting temperature $=120^{\circ} \mathrm{C}$ & The Polyolefin Company, Singapore \\
EVA & MFI $=2 \mathrm{~g} / 10$ min & \\
& Density $=0.94 \mathrm{~g} \mathrm{~cm}{ }^{-3}$ & \\
& Vicat softening point $=63^{\circ} \mathrm{C}$ & \\
& Vinyl acetate content $=18 \mathrm{wt} \%$ & Nanocor, United States \\
MMT & Modified with quarternary ammonium salt & \\
& Average particle size $=15-20 \mu \mathrm{m}$ &
\end{tabular}

Table 2: LDPE/MMT nanocomposite formulations.

\begin{tabular}{lcccc}
\hline Sample designation & LDPE $(\mathrm{wt} \%)$ & MMT $(\mathrm{wt} \%)$ & MAPE $(\mathrm{phc})^{*}$ & EVA $(\mathrm{phc}) *$ \\
\hline LDPE & 100 & 0 & 0 & 0 \\
MAPE & 0 & 0 & 100 & 0 \\
EVA & 0 & 0 & 0 & 100 \\
PEN-0 & 96 & 4 & 0 & 0 \\
PENM-1 & 96 & 4 & 1 & 0 \\
PENM-2 & 96 & 4 & 2 & 0 \\
PENM-3 & 96 & 4 & 3 & 0 \\
PENM-4 & 96 & 4 & 4 & 0 \\
PENM-5 & 96 & 4 & 5 & 0 \\
PENE-1 & 96 & 4 & 0 & 4 \\
PENE-2 & 96 & 4 & 0 & 8 \\
PENE-3 & 96 & 4 & 0 & 12 \\
PENE-4 & 96 & 4 & 0 & 16 \\
PENE-5 & 96 & 4 & 0 & 20 \\
\hline
\end{tabular}

* parts per hundred parts of composite 


\subsection{Experimental Techniques}

\subsubsection{XRD}

X-ray diffraction (XRD) analysis was used to study the intercalation of LDPE chains into the MMT layers and their degree of delamination. A Bruker D8 Advance diffractometer was used to measure the $d$-spacing of the hybrid filler-filled nanocomposite films. The diffraction patterns were obtained at room temperature in the range $2^{\circ}<2 \theta<10^{\circ}$ by step of $0.02^{\circ}$. The X-ray beam $\mathrm{Cu} \mathrm{K} \alpha$ radiation $(\lambda=0.154$ $\mathrm{nm}$ ) was operated at $30 \mathrm{kV}$ and $10 \mathrm{~mA}$. The MMT interlayer distance ( $d$-spacing) were quantified using the following equation:

$$
D_{001}=\frac{\lambda}{2 \operatorname{Sin} \theta}
$$

where $D_{001}$ is interlayer distance between clay layers, $\lambda$ is wavelength of the $\mathrm{X}$-ray beam, and $\theta$ is half of the diffraction angle at the first peak.

\subsubsection{Mechanical measurements}

The neat LDPE and the nanocomposite blown films were cut into rectangular shaped specimen $(102 \times 15 \mathrm{~mm})$ along their longitudinal direction. Micrometre (Mitutoyo, Japan) with precision $\pm 0.001 \mathrm{~mm}$ was used to measure thickness of the film samples. The mechanical measurements (tensile and tear properties) were carried out by using Lloyd's universal testing machine following the procedures described in ASTM D882 and D1938 standards, respectively. At least seven different samples were tested for each sample composition and the mean values were reported.

\subsubsection{Oxygen barrier analysis}

The oxygen $\left(\mathrm{O}_{2}\right)$ permeability coefficient measurements for the films were carried out at room temperature in a constant pressure/variable volume type permeation cell designed according to ASTM D1434-82 (Reapproved 2009). Circular film samples of uniform thickness and $4.4 \mathrm{~cm}$ diameter were used to study oxygen transmission rate (OTR, $\mathrm{ml} / \mathrm{m}^{2} / 24 \mathrm{~h}$ ). Micrometre (Mitutoyo, Japan) with precision $\pm 0.001 \mathrm{~mm}$ was used to measure film sample thickness and permeability coefficient was calculated by using the relation given below:

$$
P=t \frac{O T R}{\Delta p}
$$

where $P$ is permeability coefficient $\left(\mathrm{ml}-\mathrm{mm} / \mathrm{m}^{2} / 24 \mathrm{~h} / \mathrm{atm}\right), t$ is the film thickness $(\mathrm{mm})$, and $\Delta p$ is $\mathrm{O}_{2}$ partial pressure difference across two sides of the film (atm). 


\section{RESULTS AND DISCUSSION}

\subsection{XRD}

XRD patterns exhibit the formation of intercalated or semi exfoliated composites with the help of movement of the diffraction peak while the disappearances of this diffraction peak indicate possible exfoliation of clay platelets in the polymer matrix. The XRD diffractograms of MMT and the representative nanocomposite films having varying content of MAPE and EVA compatibiliser are shown in Figures 1(a) and (b), respectively. The figures compare influence of adding compatibiliser on the diffraction peak intensity and position of diffraction peak in general, and the effectiveness of individual compatibiliser in delaminating the MMT layers in LDPE/MMT system in particular. Neat MMT shows an XRD diffraction peak centred at about $3.45^{\circ} 2 \theta$, corresponding to interlayer spacing of $2.56 \mathrm{~nm}$.

For uncompatibilised nanocomposite films (PEN-0), the corresponding peak moved slightly toward lower $2 \theta\left(3.36^{\circ} 2 \theta\right.$, corresponding to interlayer spacing of $2.63 \mathrm{~nm}$ ), indicative of poor compatibility between MMT and LDPE. ${ }^{14,22}$ For compatibilised nanocomposite film, the comparison of diffraction peak location reveals that peak position moved toward lower $2 \theta$ and continued to move as the MAPE and EVA content increased. Adding 3 phc MAPE or 12 phe EVA into LDPE/MMT uncompatibilised system resulted in 32\% and $25 \%$ improvement in interlayer distances of the MMT. With further increase in the concentration of compatibilisers, MMT interlayer spacing increased further. For instance, the interlayer spacing increased to 3.66 and $3.42 \mathrm{~nm}$ in case of PENM-5 and PENE-5 and the interlayer distance increased to $39 \%$ and $30 \%$ respectively, when compared to uncompatibilised nanocomposite films.

Previous studies have also shown that no intercalation of polymer chains in the galleries of MMT is obtained by compounding polyethylene with MMT in the absence of compatibiliser, and the nanoclay exfoliation level in the polymer composites increases by increasing the number of polar groups. . $14,23^{1}$ Comparing the effectiveness of two different compatibilisers, it is observed that MAPE is more effective in delaminating the MMT platelets. Concerning the changes in diffraction peak intensities, the XRD diffractograms depict that neat MMT have higher diffraction peak intensity than any of the prepared nanocomposite film. This decrease in peak intensity indicates an increased disordering of MMT platelets in the nanocomposite. The decrease in the diffraction peak intensity especially with the lower content of MMT was also reported by Ataeefard and Moradian while studying the effect of MMT concentration on the polypropylene based nanocomposites. ${ }^{24}$ From the above observation, we can conclude that a significant 
amount of compatibiliser is necessary to intercalate LDPE chains in MMT interlayer galleries and to delaminate the MMT platelets for dispersion on the matrix.
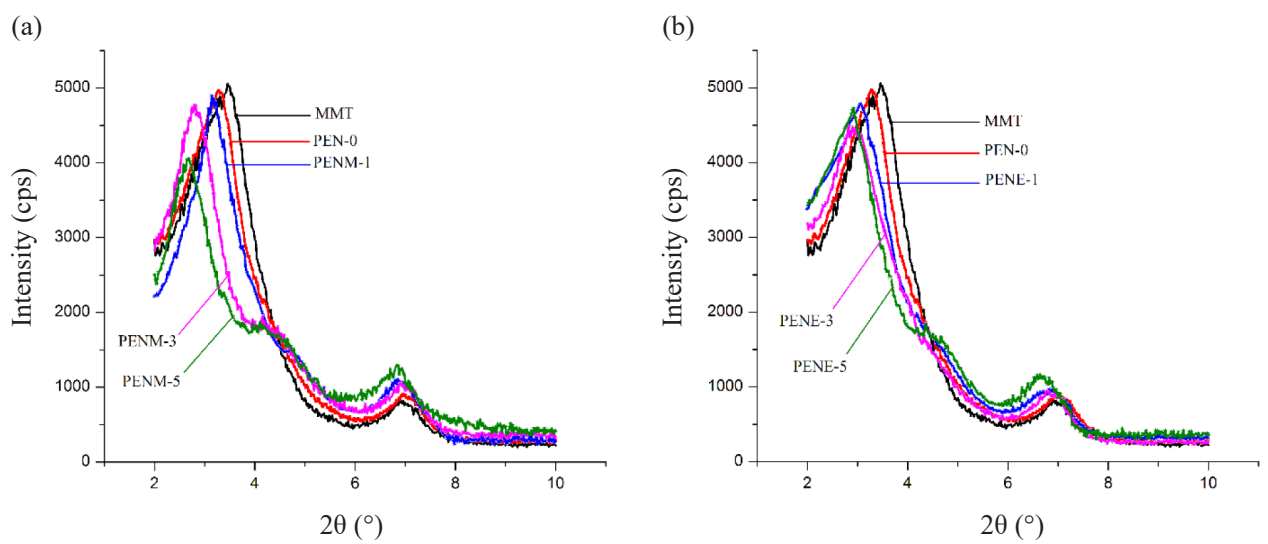

Figure 1: XRD diffractograms of neat MMT and LDPE/MMT nanocomposites with different content of (a) MAPE and (b) EVA compatibilisers.

\subsection{Mechanical Properties}

Tensile and tear properties including tensile strength, elongation at break, Young's modulus and tear strength were measured to investigate the influence of two of the compatibilisers on the aforementioned properties. Table 3 presents a comparison of MAPE and EVA compatibiliser by analysing their influence on the tensile and tear properties of LDPE/MMT nanocomposite films as a function of compatibiliser content. Tensile strength, elongation at break and Young's modulus of neat LDPE are 14.6 MPa, 220\% and 163.4 MPa, respectively, as shown in Table 3. It was observed that adding MMT into the LDPE matrix without any compatibiliser decreased tensile strength and elongation at break drastically compared to the neat LDPE. This decrease in tensile strength and elongation at break can be associated with incompatibility and lack of favourable interactions between LDPE and MMT. The decrease in elongation at break can also be attributed to the restriction in mobility of polymer chains owing to MMT content. Contrary to this decrease in tensile strength and elongation at break with the addition of MMT, Young's modulus increased remarkably. The modulus increased from 163.4 to $197.3 \mathrm{MPa}$ when compared with neat LDPE. These findings reveal that MMT reinforcing effect in LDPE/MMT nanocomposites mainly apply to the modulus. Similar results have also been reported by Swain and Isayev and Pegoretti et al. for uncompatibilised HDPE/MMT system. ${ }^{25,26}$ 
Table 3: Tensile and tear properties of LDPE based nanocomposites.

\begin{tabular}{lcccc}
\hline $\begin{array}{l}\text { Sample } \\
\text { designation }\end{array}$ & $\begin{array}{c}\text { Tensile strength } \\
(\mathrm{MPa})\end{array}$ & $\begin{array}{c}\text { Elongation at break } \\
(\%)\end{array}$ & $\begin{array}{c}\text { Young's modulus } \\
(\mathrm{MPa})\end{array}$ & $\begin{array}{c}\text { Tear strength } \\
(\mathrm{MPa})\end{array}$ \\
\hline LDPE & $14.6 \pm 1.1$ & $220 \pm 12$ & $163.4 \pm 14.2$ & $138.4 \pm 6.4$ \\
MAPE & $15.1 \pm 1.3$ & $232 \pm 17$ & $159.7 \pm 11.5$ & $137.5 \pm 4.7$ \\
EVA & $15.8 \pm 1.0$ & $447 \pm 37$ & $121.8 \pm 8.6$ & $143.2 \pm 4.1$ \\
PEN-0 & $11.2 \pm 1.4$ & $139 \pm 8$ & $197.3 \pm 11.9$ & $121.5 \pm 11.3$ \\
PENM-1 & $12.8 \pm 0.9$ & $151 \pm 11$ & $201.7 \pm 16.2$ & $129.2 \pm 9.8$ \\
PENM-2 & $13.9 \pm 1.2$ & $169 \pm 7$ & $207.2 \pm 14.4$ & $137.3 \pm 7.7$ \\
PENM-3 & $15.2 \pm 1.1$ & $177 \pm 10$ & $215.1 \pm 15.7$ & $138.7 \pm 8.3$ \\
PENM-4 & $15.5 \pm 0.7$ & $179 \pm 8$ & $217.5 \pm 13.3$ & $146.5 \pm 9.4$ \\
PENM-5 & $15.6 \pm 1.2$ & $185 \pm 11$ & $216.1 \pm 15.1$ & $142.3 \pm 8.3$ \\
PENE-1 & $11.7 \pm 0.7$ & $155 \pm 13$ & $201.5 \pm 14.3$ & $124.5 \pm 4.8$ \\
PENE-2 & $12.4 \pm 0.4$ & $171 \pm 9$ & $204.4 \pm 16.4$ & $131.8 \pm 6.7$ \\
PENE-3 & $13.3 \pm 0.9$ & $185 \pm 13$ & $195.6 \pm 19.0$ & $136.6 \pm 7.1$ \\
PENE-4 & $13.2(1.1)$ & $204 \pm 14$ & $187.3 \pm 18.1$ & $137.2 \pm 10.2$ \\
PENE-5 & $13.4(0.8)$ & $227 \pm 10$ & $173.4 \pm 14.7$ & $135.6 \pm 9.0$ \\
\hline
\end{tabular}

In order to enhance the interfacial adhesion between LDPE/MMT system, MAPE and EVA compatibilising agents were used and their amounts were varied to investigate their loading influence on the properties. From Table 3, it is clear that adding compatibiliser to the uncompatibilised nanocomposite system resulted in significant increase in the tensile properties. Tensile strength and elongation at break of the nanocomposite films compatibilised with both of the compatibilisers continued to increase as the compatibiliser concentration increased. The values of tensile strength for LDPE/MMT nanocomposite films compatibilised 3 phc MAPE and 12 phe EVA increased by $36 \%$ and 19\% respectively, when compared with uncompatibilised films. Concerning Young's modulus, the value started increasing gradually for increasing MAPE content from 0 to 3 phc. Interestingly, expected improvement in modulus owing to elevated amounts of MAPE compatibiliser $(3-5 \mathrm{wt} \%)$ that resulted in better interfacial adhesion is not happen, and an optimal amount of MAPE can be found at $3 \mathrm{wt} \%$. Further, the modulus of EVA compatibilised nanocomposite films remained practically unchanged with up to $8 \mathrm{wt} \%$ content and started decreasing with further EVA content. This decrease can be attributed to plasticising effect of EVA. Dadfar et al. and Behradfar et al. have also reported a similar trend for EVA compatibilised LDPE/MMT system. ${ }^{14,27}$ On the contrary, Hosseinkhanli et al. observed an increase in all the tensile properties for LDPE/MMT system compatibilised with $20 \%$ EVA when compared with uncompatibilised system. ${ }^{16}$ 
Tear strength is the resistance to the growth of a cut or nick in a specimen when tension is applied, and is another important property for high capacity pouches, bags and other industrial applications. Table 3 displays the tear propagation strength for the studied samples. Results revealed that for uncompatibilised nanocomposite films, the tear propagation strength decreases with MMT addition versus virgin LDPE. However, adding MAPE compatibiliser increased the strength and recovered to the neat LDPE value at 3 phc MAPE. It increased further with increasing the compatibiliser concentration and 6\% improvement in comparison to neat LDPE was observed, with the addition of 4 phc MAPE. Adding EVA compatibiliser to the uncompatibilised LDPE/MMT increased the tear strength as well and continued to increase proportionally to EVA content. Comparatively, the influence of MAPE compatibiliser is more significant in enhancing tear strength than EVA, as do the tensile strength. The increased tear strength with the incorporation of compatibiliser can be attributed to improved interfacial adhesion that impedes tear propagation.

\subsection{Oxygen Barrier Properties}

Oxygen $\left(\mathrm{O}_{2}\right)$ deleterious effect on the quality of a wide variety of food products is well documented in literature. ${ }^{28,29}$ It is responsible for lipid oxidation, microorganism growth, enzymatic browning and vitamin loss. Thus, the development of packaging materials that can reduce/retard the food oxidation is necessary not only to maintain quality but also to prolong the shelf life. Oxygen permeability of neat LDPE, MAPE and EVA are 224, 215 and $578 \mathrm{ml}-\mathrm{mm} / \mathrm{m}^{2}$ d-atm, respectively. These results suggest that the permeability of LDPE and MAPE are quite comparable, whereas there is a big difference between that of LDPE and EVA, as well as MAPE and EVA. Similar observations have also been reported by other researchers. ${ }^{30,31}$ Adding MMT into the LDPE matrix without any compatibiliser increased the oxygen barrier compared to the neat LDPE as shown in Figure 2. It is believed that MMT layers are impermeable obstacles in the path of diffusing molecules. Thus, this increase in barrier can be associated with decrease in free volume fraction as a result of substituting an impermeable MMT layers with a fraction of a permeable polymer. Adding MAPE into LDPE/ MMT nanocomposite system resulted in further increase in barrier and this progressive increase continued with increasing MAPE content (Figure 2). It is also worth mentioning that the increase in barrier with the addition of MAPE is more prominent at lower content than beyond 3 phc. Of note is PENM-3 where 3 phc MAPE addition resulted in almost 39\% improvement in oxygen barrier when compared to neat LDPE. Oxygen permeability reduced further with increasing MAPE concentration however, reduction is not as significant as in the case of PENM-3. The permeability reduced to $44 \%$ and $46 \%$ with the addition of 4 and 5 phc MAPE compatibiliser, respectively. This reduction in permeability is 
due to the delamination and distribution of impermeable clay platelets that act as obstacles in the path of the diffusing molecules. These impermeable obstacles force the diffusing molecules to follow a tortuous path, which in turn, retards/reduce the gas molecule diffusion. ${ }^{32}$ Furthermore, increasing the MAPE concentration improves the interfacial adhesion of clay platelets with the matrix material that leads to the improved barrier properties. These findings are consistent with our XRD observations and mechanical measurements. Decrease in permeability and increase in oxygen barrier for LDPE/MMT nanocomposite films compatibilised with MAPE compatibiliser is also reported by other researchers. ${ }^{18,33}$

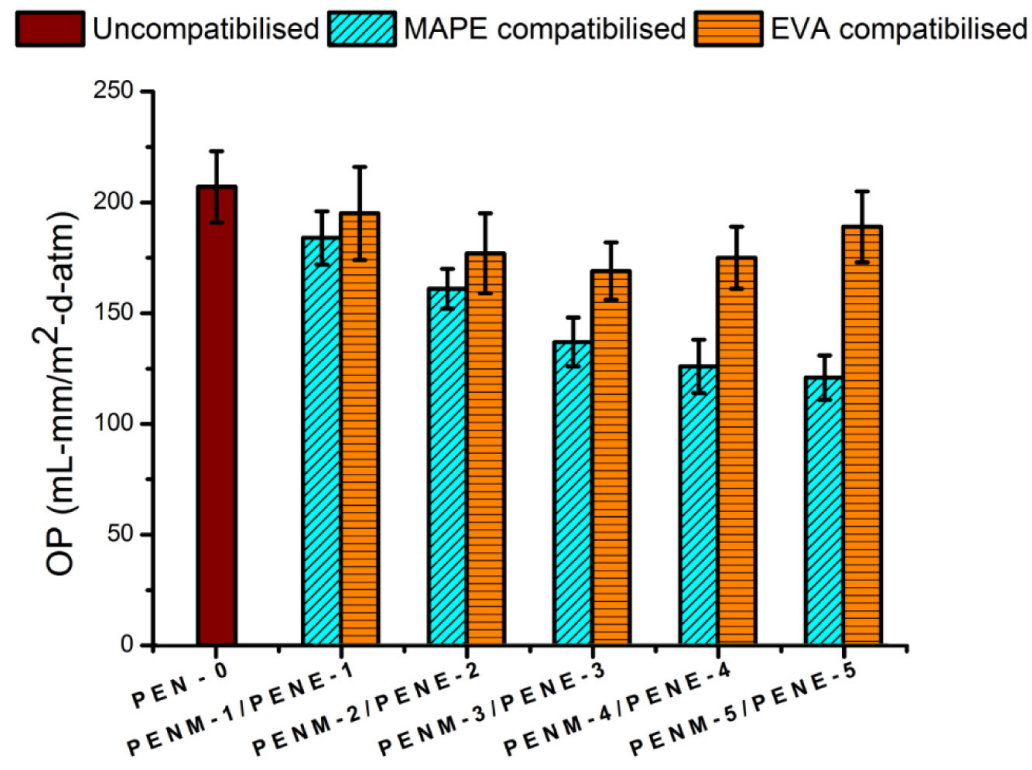

Figure 2: Oxygen permeability of LDPE/MMT nanocomposites with different contents of MAPE and EVA compatibilisers.

Concerning EVA compatibilised nanocomposite films, adding EVA resulted in decrease in oxygen permeability. This decrease in oxygen permeability of LDPE/ MMT is not a linear function of EVA content and the permeability is minimum at 12 phc EVA (PENE-3). Decrease in permeability arises from the longer diffusive path that the penetrants must travel in the presence of impermeable obstacles. ${ }^{34}$ Increasing the EVA content beyond 12 phc resulted in deteriorating the oxygen barrier of LDPE/MMT nanocomposite films (PENE-4 and PENE-5). This is conflicting with our XRD observation where diffraction peak moved toward lower $2 \theta$ (indicative of intercalation of polymer chains in the galleries of MMT) and continued to with increasing the EVA content. The large side groups of EVA affect the structure of PE crystal units, contributing to a lower oxygen barrier with the 
presence of EVA. ${ }^{14}$ Also EVA is more permeable than LDPE and this increase in permeability may be because of higher content of high permeable material. ${ }^{35}$ Dadfar et al. have also reported the increase in oxygen permeability with increasing EVA concentration in HDPE/EVA/MMT system. ${ }^{36}$

\section{CONCLUSION}

Food packaging with enhanced mechanical and barrier properties is constantly sought in response to the consumer concerns for health consciousness, food safety and market globalisation. In this study, MAPE and EVA compatibilisers were used in different concentrations to evaluate their role in delaminating MMT platelets in LDPE matrix and helping their uniform dispersion in the matrix. X-ray diffractograms showed no intercalation of LDPE chains in the galleries of MMT for uncompatibilised system. On the other hand, compatibilised nanocomposites illustrate that upon incorporation of MAPE and EVA, the diffraction peak shifts to smaller $2 \theta$ value, indicating an increase in the $d$-spacing. For instance, incorporation of 3 phe MAPE and 12 phe EVA into LDPE/MMT nanocomposite led to 32\% and $25 \%$ improvement in interlayer distances of the MMT, respectively. Increase in interlayer spacing suggest the delamination/disordering of MMT platelets and their ultimate dispersion in the polymer matrix. In addition, the tensile and tear properties of MAPE and EVA compatibilised LDPE/MMT nanocomposites are better than those of uncompatibilised ones. The optimum contents of MAPE and EVA in LDPE/MMT nanocomposites based on mechanical and permeability results are 3 and 12 phc, respectively.

As comparison, LDPE/MMT/MAPE nanocomposites showed better mechanical and barrier properties than those of LDPE/MMT/EVA nanocomposites. Furthermore, incorporation of MAPE into LDPE/MMT nanocomposites resulted in significant increase in oxygen barrier which increased with increasing MAPE content. It is also observed that the reduction in permeability due to delamination of MMT platelets as a result of MAPE addition is quite significant at 3 phc MAPE addition while a slight reduction beyond 3 phe is observed. The addition of EVA also resulted in decrease in oxygen permeability and the permeability is minimum at 12 phe EVA. The minimum permeability values for MAPE and EVA compatibilised nanocomposite films are 121 and $169 \mathrm{ml}-\mathrm{mm} / \mathrm{m}^{2}$-d-atm, respectively.

\section{ACKNOWLEDGEMENTS}

The authors wish to acknowledge the Universiti Teknologi Malaysia (UTM) and Fundamental Research Grant Scheme (FRGS) 7825 and 7844, sub-codes: 3F302 
and 4F525, respectively, and Ministry of Higher Education (MOHE) for financial support. In addition, the authors also wish to acknowledge the Research University Grant (RUG) 2544, sub-code: $10 \mathrm{H} 94$ for financial support.

\section{REFERENCES}

1. Marsh, K. \& Bugusu, B. (2007). Food packaging-roles, materials, and environmental issues. J. Food Sci., 72(3), R39-R55, https://doi.org/10.1111/ j.1750-3841.2007.00301.x.

2. Chinkamonthong, R., Kositchaiyong, A. \& Sombatsompop, N. (2013). Effects of thermal and UV aging on antibacterial properties of linear low-density polyethylene and poly (vinyl chloride) films containing nano-silver colloid. J. Plast. Film Sheet., 29(2), 144-162, https://doi. org/10.1177/8756087912464967.

3. Kurek, M. et al. (2012). Barrier properties of chitosan coated polyethylene. J. Membr. Sci., 403, 162-168, https://doi.org/10.1016/j.memsci.2012.02.037.

4. Tartakowski, Z. (2010). Recycling of packaging multilayer films: New materials for technical products. Resour. Conserv. Recy., 55(2), 167-170, https://doi.org/10.1016/j.resconrec.2010.09.004.

5. Xie, L. et al. (2012). Preparation and performance of high-barrier low density polyethylene/organic montmorillonite nanocomposite. Polym.Plast. Technol. Eng., 51(12), 1251-1257, https://doi.org/10.1080/0360255 9.2012.699131.

6. Kawasumi, M. (2004). The discovery of polymer-clay hybrids. J. Polym. Sci. Pol. Chem., 42(4), 819-824, https://doi.org/10.1002/pola.10961.

7. Ray, S. et al. (2006). The potential use of polymer-clay nanocomposites in food packaging. Int. J. Food Eng., 2(4), 1149, https://doi.org/10.2202/15563758.1149 .

8. Guduri, B. R. \& Luyt, A. S. (2007). Comparison of the influence of different compatibilizers on the structure and properties of ethylene vinyl acetate copolymer/modified clay nanocomposites. J. Appl. Polym. Sci., 105(6), 3612-3617, https://doi.org/10.1002/app.26532.

9. Hong, S. I. \& Rhim, J. W. (2012). Preparation and properties of meltintercalated linear low density polyethylene/clay nanocomposite films prepared by blow extrusion. LWT-Food Sci. Technol., 48(1), 43-51, https://doi.org/10.1016/j.1wt.2012.03.009.

10. Pereira de Abreu, D. A. et al. (2007). Development of new polyolefin films with nanoclays for application in food packaging. Eur. Polym. J., 43(6), 2229-2243, https://doi.org/10.1016/j.eurpolymj.2007.01.021. 
11. Chiu, F. C., Yen, H. Z. \& Lee, C. E. (2010). Characterization of PP/HDPE blend-based nanocomposites using different maleated polyolefins as compatibilizers. Polym. Test., 29(3), 397-406, https://doi.org/10.1016/j. polymertesting.2010.01.004.

12. Minkova, L. \& Filippi, S. (2010). Polymer-clay nanocomposites based on blends of various types of polyethylenes and PE-g-MA: Morphology, thermal properties, microhardness, and transparency. J. Macromol. Sci. Part B-Phys., 49(6), 1136-1147, https://doi.org/10.1080/00222341003609856.

13. Hamim, F. A. R., Abdul Ghani, S. \& Zainudin, F. (2016). Properties of recycled high density polyethylene (RHDPE)/ethylene vinyl acetate (EVA) blends: The effect of blends composition and compatibilisers. J. Phys. Sci., 27(2), 23-39.

14. Dadfar, S. A. et al. (2011). Studies on the oxygen barrier and mechanical properties of low density polyethylene/organoclay nanocomposite films in the presence of ethylene vinyl acetate copolymer as a new type of compatibilizer. Mater. Design., 32(4), 1806-1813, https://doi.org/10.1016/j. matdes.2010.12.028.

15. Marini, J. et al. (2010). Effect of EVA as compatibilizer on the mechanical properties, permeability characteristics, lamellae orientation, and long period of blown films of HDPE/clay nanocomposites. J. Appl. Polym. Sci., 118(6), 3340-3350, https://doi.org/10.1002/app.32356.

16. Hosseinkhanli, H. et al. (2013). Oxygen permeability and the mechanical and thermal properties of (low-density polyethylene)/poly (ethylene-covinyl acetate)/organoclay blown film nanocomposites. J. Vinyl Addit. Techn., 19(2), 132-139, https://doi.org/10.1002/vnl.20329.

17. Valera-Zaragoza, M. et al. (2006). Thermal stability and flammability properties of heterophasic PP-EP/EVA/organoclay nanocomposites. Polym. Degrad. Stab., 91(6), 1319-1325, https://doi.org/10.1016/j. polymdegradstab.2005.08.011.

18. Zhong, Y. et al. (2007). Mechanical and oxygen barrier properties of organoclay-polyethylene nanocomposite films. Polym. Eng. Sci., 47(7), 1101-1107, https://doi.org/10.1002/pen.20792.

19. Dadbin, S., Noferesti, M. \& Frounchi, M. (2008). Oxygen barrier LDPE/ LLDPE/organoclay nano-composite films for food packaging. Macromol. Symp., 274(1), 22-27, https://doi.org/10.1002/masy.200851404.

20. Azizi, S., Wan Yunus, W. M. Z. \& Ahmad, M. (2011). Effect of polyethylenegrafted maleic anhydride on properties of high-density polyethylene polystyrene blend/layered silicate nanocomposites. J. Reinf. Plast. Compos., 30(19), 1649-1654, https://doi.org/10.1177/0731684411426626. 
21. Zanetti, M. \& Costa, L. (2004). Preparation and combustion behaviour of polymer/layered silicate nanocomposites based upon PE and EVA. Polym., 45(13), 4367-4373, https://doi.org/10.1016/j.polymer.2004.04.043.

22. Majeed, K., Hassan, A., \& Bakar, A. A. (2014). Influence of maleic anhydride-grafted polyethylene compatibiliser on the tensile, oxygen barrier and thermal properties of rice husk and nanoclay-filled low-density polyethylene composite films. J. Plast. Film Sheet., 30(2), 120-140, https://doi.org/10.1177/8756087913494083.

23. Martín, Z. et al. (2009). Spectromicroscopy study of intercalation and exfoliation in polypropylene/montmorillonite nanocomposites. J. Phys. Chem. B, 113(32), 11160-11165, https://doi.org/10.1021/jp9049999.

24. Ataeefard, M. \& Moradian, S. (2011). Polypropylene/organoclay nanocomposites: Effects of clay content on properties. Polym.-Plast. Technol. Eng., 50(7), 732-739, https://doi.org/10.1080/03602559.2010.551438.

25. Swain, S. K. \& Isayev, A. I. (2007). Effect of ultrasound on HDPE/clay nanocomposites: Rheology, structure and properties. Polym., 48(1), 281289, https://doi.org/10.1016/j.polymer.2006.11.002.

26. Pegoretti, A., Dorigato, A. \& Penati, A. (2007). Tensile mechanical response of polyethylene-clay nanocomposites. Express Polym. Lett., 1(3), 123-131, https://doi.org/10.3144/expresspolymlett.2007.21.

27. Behradfar, A., Shojaei, A. \& Sheikh, N. (2010). Rheological and mechanical characteristics of low density polyethylene/ethylene-vinyl acetate/organoclay nanocomposites. Polym. Eng. Sci., 50(7), 1315-1325, https://doi.org/10.1002/pen.21660.

28. Ayranci, E. \& Tunc, S. (2003). A method for the measurement of the oxygen permeability and the development of edible films to reduce the rate of oxidative reactions in fresh foods. Food Chem., 80(3), 423-431, https://doi.org/10.1016/S0308-8146(02)00485-5.

29. Bonilla, J. et al. (2012). Edible films and coatings to prevent the detrimental effect of oxygen on food quality: Possibilities and limitations. J. Food Eng., 110(2), 208-213, https://doi.org/10.1016/j.jfoodeng.2011.05.034.

30. Horst, M. F., Quinzani, L. M. \& Failla, M. D. (2012). Rheological and barrier properties of nanocomposites of HDPE and exfoliated montmorillonite. J. Thermoplast. Compos. Mater., 27(1), 106-125, https://doi.org/10.1177/0892705712443248.

31. Goodarzi, V. et al. (2013). Assessment of role of morphology in gas permselectivity of membranes based on polypropylene/ethylene vinyl acetate/clay nanocomposite. J. Membr. Sci., 445, 76-87, https://doi. org/10.1016/j.memsci.2013.04.073. 
32. Khalili, S., Masoomi, M. \& Bagheri, R. (2013). The effect of organo-modified montmorillonite on mechanical and barrier properties of linear low-density polyethylene/low-density polyethylene blend films. J. Plast. Film Sheet., 29(1), 39-55, https://doi.org/10.1177/8756087912441175.

33. Hemmati, M. et al. (2011). Study of a polymer blend/nanoclay nanocomposite of polyethylene and polyamide 6 prepared by mechanical blending. Polym.Plast. Technol. Eng., 51(1), 80-85, https://doi.org/10.1080/03602559.2011. 617410.

34. Shafiee, M. \& Ramazani, S. A. (2008). Investigation of barrier properties of poly(ethylene vinyl acetate)/organoclay nanocomposite films prepared by phase inversion method. Macromol. Symp., 274(1), 1-5, https://doi. org/10.1002/masy.200851401.

35. John, B. et al. (2011). The effects of blend ratio, compatibilization and dynamic vulcanization on permeation of gases through HDPE/EVA blends. J. Polym. Res., 18(5), 1101-1109, https://doi.org/10.1007/s10965-0109512-3.

36. Dadfar, S. R., Ramazani, S. A. \& Dadfar, S. A. (2009). Investigation of oxygen barrier properties of organoclay/HDPE/EVA nanocomposite films prepared using a two-step solution method. Polym. Compos., 30(6), 812819, https://doi.org/10.1002/pc.20711. 